\title{
Friedrich Melchior Grimm, Correspondance littéraire, t. VIII
}

\section{Francesca Pagani}

\section{(2) OpenEdition}

1 Journals

\section{Edizione digitale}

URL: http://journals.openedition.org/studifrancesi/4377

DOI: 10.4000/studifrancesi.4377

ISSN: 2421-5856

\section{Editore}

Rosenberg \& Sellier

\section{Edizione cartacea}

Data di pubblicazione: 1 settembre 2016

Paginazione: 331

ISSN: 0039-2944

\section{Notizia bibliografica digitale}

Francesca Pagani, «Friedrich Melchior Grimm, Correspondance littéraire, t. VIII », Studi Francesi [Online], 179 (LX | II) | 2016, online dal 01 septembre 2016, consultato il 18 septembre 2020. URL : http:// journals.openedition.org/studifrancesi/4377 ; DOI : https://doi.org/10.4000/studifrancesi.4377

Questo documento è stato generato automaticamente il 18 settembre 2020.

\section{(c) (i) $\odot$}

Studi Francesi è distribuita con Licenza Creative Commons Attribuzione - Non commerciale - Non opere derivate 4.0 Internazionale. 


\title{
Friedrich Melchior Grimm, Correspondance littéraire, t. VIII
}

\author{
Francesca Pagani
}

\section{NOTIZIA}

FRIEDRICH MELCHIOR GRIMM, Correspondance littéraire, t. VIII, 1761, édition critique de Ulla K ölving, avec la collaboration de Else Marie Bukdhal et Mélinda Caron, Ferney-Voltaire, Centre International d'étude du XVIII ${ }^{\mathrm{e}}$ siècle, 2013, LXX + 524 pp.

1 Dal 2006 il Centre International d'étude du XvIII siècle propone, sotto la direzione di Ulla Kölving, un'edizione critica dedicata alla Correspondance littéraire di Grimm, volta a sostituire quella di Tourneux, ritenuta ormai superata. Questo volume, l'ottavo della collana, abbraccia l'anno 1761, periodo particolarmente avverso per Grimm in ragione dell'accusa di spionaggio che gli fu mossa a seguito dell'intercettazione di alcune sue lettere a Paul-Henri Mallet; questo evento lo fece cadere in disgrazia e ne determinò il ritiro dalla scena diplomatica.

2 Il tomo, in sintonia con i precedenti della serie, si apre con un'introduzione che illustra le attività svolte da Grimm in quell'anno e mette in luce il contesto politico - francese e internazionale - e quello letterario e artistico del medesimo periodo. La Correspondance littéraire di Grimm è messa quindi in relazione con gli altri periodici, manoscritti o stampati, del 1761; la sezione conclusiva dell'ampia e dettagliata introduzione dà conto della diffusione della Correspondance, dei suoi abbonati, dei collaboratori, dei copisti, e restituisce la specificità dei manoscritti considerati per la presente edizione.

3 I testi della Correspondance littéraire, suddivisi in 24 sezioni, comprendono sia gli scritti firmati da Grimm e dai suoi collaboratori, sia quelli inviati contestualmente al periodico, di cui costituiscono dunque parte integrante. Seguono due appendici, l'una dedicata agli scritti di Louise d'Épinay, inseriti nella Correspondance del 1761 (tre dialoghi filosofici e il racconto Qu'en pensez-vous?), l'altra relativa agli interventi di Grimm nel testo autografo di Diderot del Salon dello stesso anno. 
4 Un'annotazione rigorosa e dettagliata permette di identificare le opere, le persone e gli eventi menzionati da Grimm; di pari efficacia gli indici dei titoli, degli incipit delle opere versificate, e quello generale, che racchiude i nomi propri, di persona, di istituzioni, di luoghi, di popoli, di artisti e autori.

5 Questa pubblicazione, certamente encomiabile, offre una ricca testimonianza di quell'intreccio tra i saperi che contraddistinse l'età dei Lumi, e si configura pertanto come una fonte preziosa, suscettibile di interessare vari ambiti disciplinari nelle ricerche a venire. 